\title{
A Cross-disciplinary Approach to BlM-based Façade Design for Wind Performance
}

\section{ChungYin Kwong, Christiane M. Herr, and Theofanis Krevaikas}

Xi’an Jiao Tong Liverpool University, Suzhou, China

\section{Abstract}

This paper examines a cross-disciplinary approach to a high-rise façade design proposal for Hong Kong where the initial architectural design concept provides a negotiable boundary for an architectural engineering design process. A crucial aspect of this process is the consideration of high wind loads on the façade, as they frequently occur in Hong Kong due to regularly occurring typhoons. Design for wind performance is typically outside of the expertise of architectural designers and thus requires close collaboration between architects and structural engineers. Conventionally trained structural engineers may however not be accustomed to work with unusual building form or to consider architectural design ideas as part of engineering proposals. In

Corresponding Author: ChungYin Kwong ChungYin.kwong15@student xjtlu.edu.cn

Received: 15 March 2019

Accepted: 25 May 2019

Published: 20 November 2019

Publishing services provided by Knowledge E

(c) ChungYin Kwong et al. This article is distributed under the terms of the Creative Commons Attribution License, which permits unrestricted use and redistribution provided that the original author and source are credited

Selection and Peer-review under the responsibility of the Architecture across Boundaries Conference Committee.

\section{Background}

In the design of buildings, architects typically lead the project by creating the overall design idea, whereas structural engineers are more likely to respond to the structural challenges established by the architectural proposal by means of structural dimensioning and calculations. From the perspective of the engineer, architectural proposals tend to be understood as hard boundaries for the engineering design process. From an architectural viewpoint, boundaries are understood as constraints that can be renegotiated if this promises to improve the quality of an overall design proposal. In crossdisciplinary design practice, mutual understanding of these perspectives is required to make informed design exploration possible [1]: To maintain a broad range of options during the design process, knowledge from both disciplines is necessary.

The project discussed in this paper illustrates a disciplinary cross-over during the design process of a façade for a high-rise building located in Hong Kong. The overall design proposal was developed as part of a MArch Des thesis project by Chitraj BIM 
Bissoonauth at Xi'an Jiaotong-Liverpool University [2]. The architectural design aim for the facade is to extend limited living space in high density residential architecture of Hong Kong and to create higher quality high rise living. To this end, the architectural designer proposes an extension of Hong Kong's urban coastline of the Kennedy Town area on Hong Kong Island, into the waters of Victoria Harbour. In the high density residential high rises of Hong Kong, inhabitants tend to make up for the lack of natural urban green by placing potted plants on the exterior of buildings, typically on top of the ubiquitous air conditioners or on the dryer racks located on the façades of the buildings, creating diverse safety issues [3] Taking a cue from these observations, the design concept integrates green space and semi-external space for residents in a "deep" façade system. While extending quality living space in this manner, the façade proposal also needs to deal with Hong Kong's polluted environment and subtropical climate. According to data collected by the Hong Kong Observatory from 1961 to 2009 , Hong Kong is affected by around 4 6 typhoons every year [4]. At the same time, the site location of the project on reclaimed land, extending out into the sea, leads to a particularly low orography factor. Despite the high wind speeds typically encountered in this building type and location, natural ventilation for Hong Kong's residential spaces is a major factor in reducing the energy consumed as well as pollution and heat generated by conventional air conditioning units. These key issues posit the challenge of the façade design between resisting wind pressure on the façade for safety on one hand, and creating a livable and naturally ventilated semi-external space on the other hand.

While the architectural proposal created a coherent and well received vision of high-rise, high- density living, available time as well as available engineering skills initially did not permit a rigorous and detailed development of the façade system. This became possible when the initial architectural design project was followed through to a second design stage as part of the Final Year Project of the first author in the Bachelor of Architectural Engineering programme [5]. During this second stage, the author collaborated with the architectural designer to develop a revised façade system satisfying both architectural design aims as well as structural engineering requirements.

To address the engineering challenge in this project, the façade design employs BIM as a platform for exchange between architect and engineer during the conceptual design stage [6]. An architectural conceptual 3D model in Rhinoceros3D is used as exchange platform for building information in this project, linking between architectural modelling software and wind performance simulation software. BIM, understood here as a collaborative digitally organized workflow rather than a specific software tool, is rapidly gaining importance in cross-disciplinary design processes. BIM provides the 
possibility to link architectural design intentions as expressed in form with performance testing early on and offers a flexible platform for cross-disciplinary design processes but is not widely embraced in this function in the local Chinese construction industry [7].

\section{Preliminary Analysis of the Conceptual Model}

\subsection{Façade boundary setting}

The architectural conceptual 3D model (Figure 1, left) in this project was exchanged between architect and engineer in the form of a Rhino3D object which defined the shape of the slabs for each floor. The external shape is loosely defined by the floor edges which form an envelope around the building. In order to implement an initial wind pressure analysis of the building for design purposes, the 3D model is used to define the inner façade that determines the boundary between indoor and semiexternal space. To maintain flexibility of the architectural layout, parametric modeling is used to define the boundary of the façade system through restructuring the architectural volume's geometric properties, and by generating curves for each floor. From this data, the maximum area between upper and lower floor generates the maximum floor plan area. Closely following the architectural concept, the façade is thus defined as shown in Figure 1, through the rationalised parametric model.
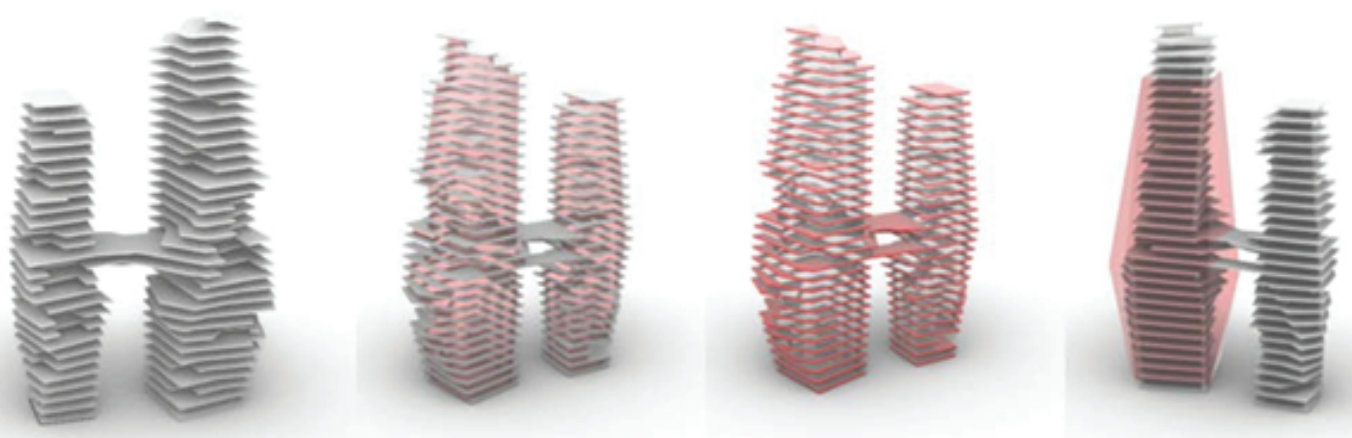

Figure 1: From left: Initial architectural concept model and 3D modelling of façade system boundaries for the inner façade, semi-external façade, and external façade.

\subsection{Inner façade wind pressure simulation}

In order to improve wind blocking performance of the initially given façade proposal, first priority is given to developing a better understanding of how the building behaves under extreme wind velocities as they will happen in a typhoon. The computational 
fluid dynamics (CFD) method is used in this project as initial wind performance testing tool to give insight into the feasibility of the architectural design. The parameter setting in the CFD software (Figure 2) is detailed in table 1 below.
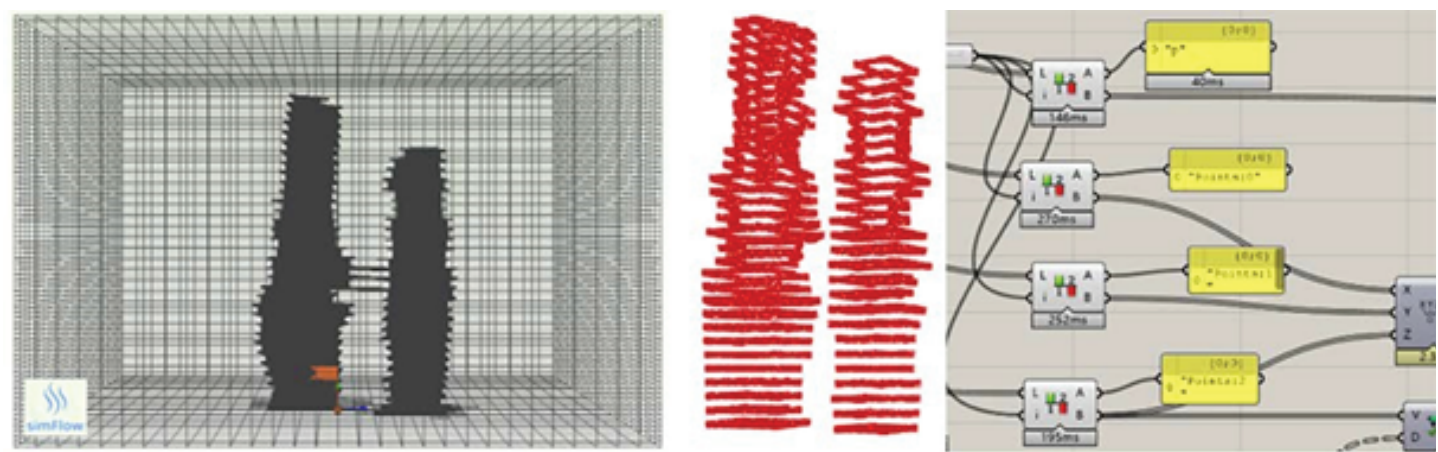

Figure 2: Boundary setting of CFD simulation (250m*225m*180m), inner façade point cloud selection.

To determine the maximum and minimum values of the inner façade boundary where larger areas of glass facade elements are located, point cloud data generated from Rhino3D is used as input for the CFD modelling software simFlow (Figure 2, right).

TABLE 1: Background setting of CFD simulation.

\begin{tabular}{|c|c|}
\hline Reference wind velocity at the level of $10 \mathrm{~m}$ & $45 \mathrm{~m} / \mathrm{s}$ \\
\hline Turbulence modelling & RANS k-epsilon model \\
\hline Boundary condition & Atmospheric Inlet \\
\hline Roughness length & 0.003 \\
\hline Ground level & 0 \\
\hline Wind Direction & $0,45,90,135,180,225,270,315$ (Degrees) \\
\hline
\end{tabular}

\subsection{Results of inner façade pressure behavior analysis}

Results generated from the CFD simulation show maximum and minimum wind pressure acting on the surface of each building floor in each of the 8 analysed potential wind directions. The resulting data can be plotted as shown in Figure 3, where the $\mathrm{Y}$ axis shows the height of the building and the $X$ axis denotes the maximum and minimum values of the 8-directional wind pressure data (positive and negative). The diagram shows that the wind pressure acting on the inner façade can be separated into two areas in the case of this building, with Level 22 acting as a division line for different wind pressure patterns. For the inner façade, this implies that types of glass or other vertical panel materials used for the facade can be selected and dimensioned in two batches in the detail design stages. 

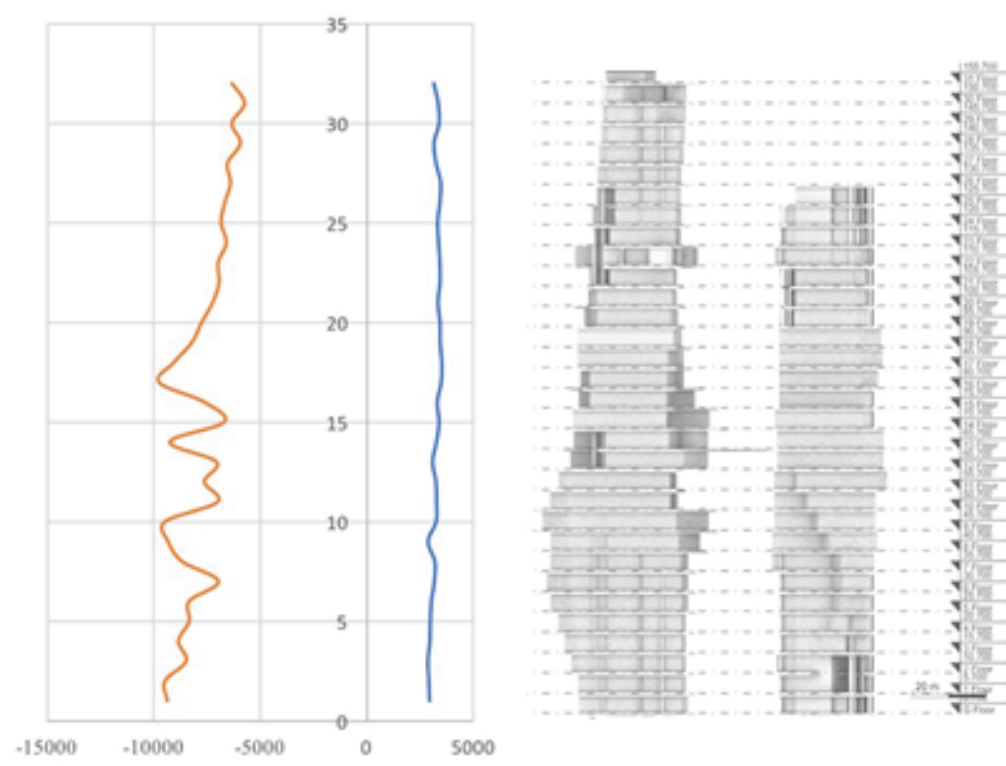

Figure 3: Maximum and minimum wind pressure acting on inner façade in 8 directions.

\section{Exterior Façade Design Procedure}

\subsection{Engineering concept for exterior façade design}

To support the architectural concept of creating a livable, naturally ventilated zone in a semi-external façade space even on high floors, several strategies were proposed to mitigate excessive and uncomfortable wind speeds (Figure 4). Wind flow can be blocked and reoriented such that the maximum wind velocity is directed away from the façade through physical façade features following non-linear velocity gradient theory. At the same time, wind is partially able to flow within semi-external façade layers to minimise the Venturi effect.
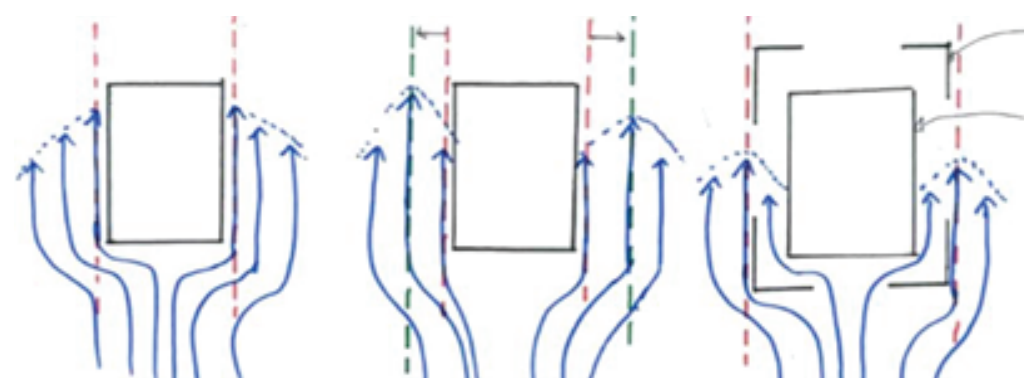

Figure 4: Wind engineering strategy for livable space design for semi-external space in high-rises. 


\subsection{Architectural concept design (Architect's feedback)}

Feedback provided from the architect supported the integrated external façade system (Figure 5). The key idea to be kept for the external façade is to design it in the form of different layers, with in between spaces of different layers available for plants and semi-external living spaces.

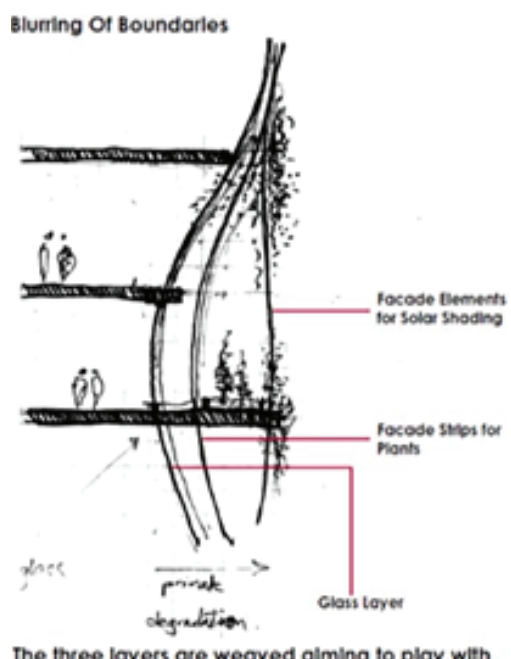

three layers or.
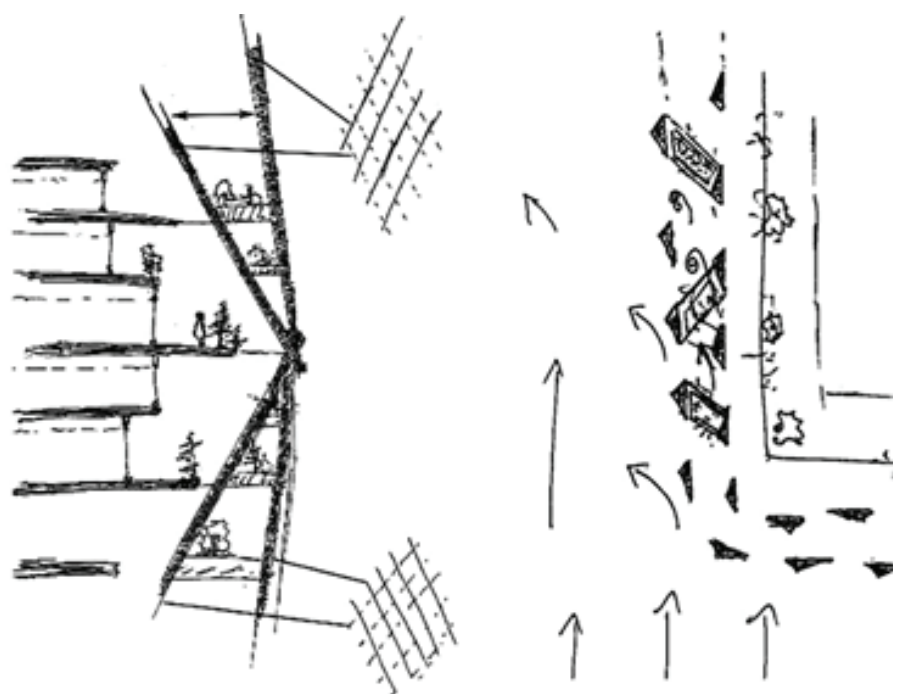

Figure 5: Architectural façade concept (left), initial engineering concept sketches of double layer facade in section and plan.

\subsection{Extending the façade design based on the engineering con- cept}

The external façade aims to integrate both architectural and engineering concept. Based on the architectural concept, the engineer provided different options for façade design proposals as shown in the following, implementing the initial design concept with some modifications for improved wind blocking performance.

\subsubsection{Double / single layer façade}

The double layer façade option aims to decrease the wind velocity in the semi-external space based on the engineering concept of non-linear velocity gradient theory, such that wind speed conditions in semi external space become more suitable to human occupation. 


\subsubsection{External façade cross section}

The shape of the cross section of the external façade elements influences the wind blocking performance significantly. In this project, the design of the cross section of external façade elements is thus based on the CFD analysis results of monitoring the wind velocity of different shapes' cross sections.

\subsubsection{Glass railing location}

To further decrease the wind velocity in the semi-external façade, the influence of railing elements is additionally taken into account. Through comparing the different effects of railings located at different heights, wind blocking performance can be further improve. In this project, railing from the floor level to $1.3 \mathrm{~m}$ height and railing from $1 \mathrm{~m}$ above the floor level to $2.5 \mathrm{~m}$ height (Figure 6 ) is tested for wind blocking performance.
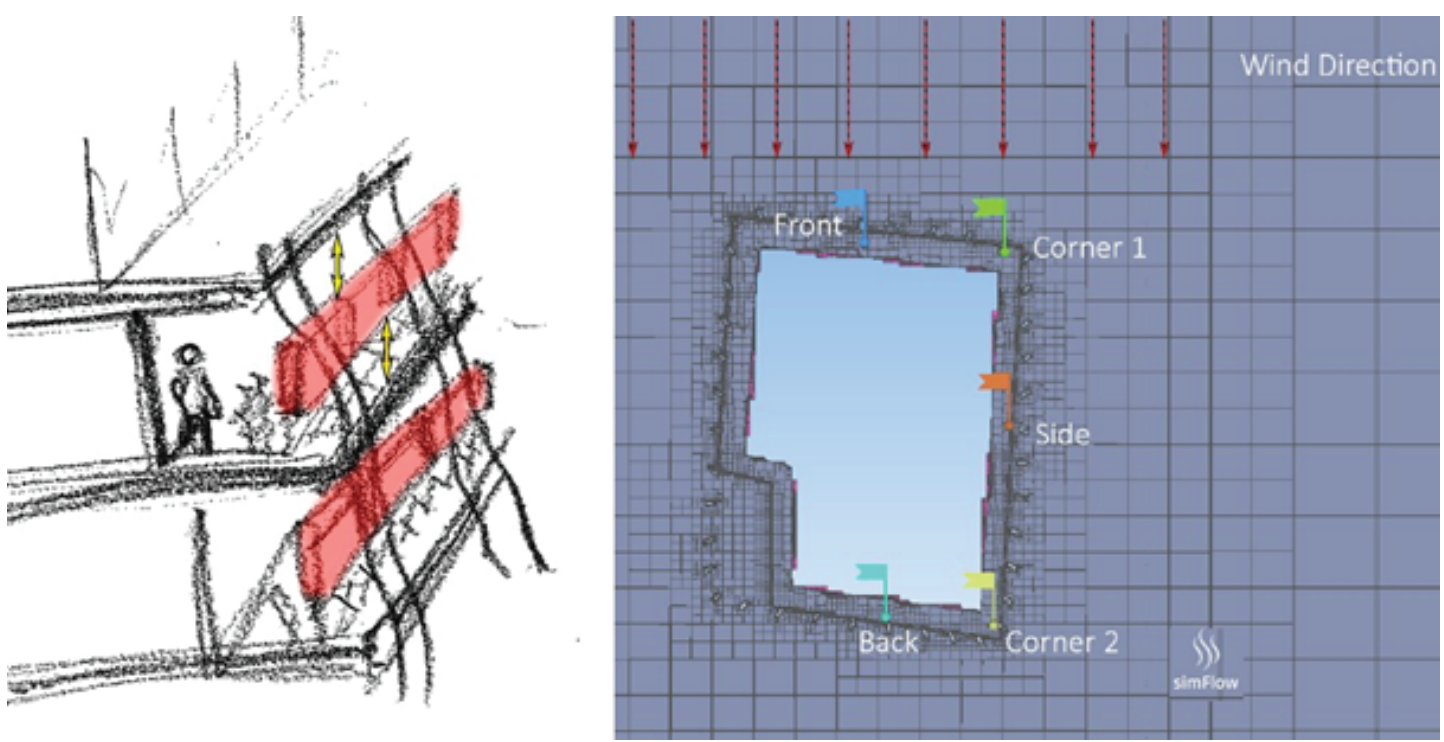

Figure 6: concept of mid-height of railing design (left), reference points in CFD simulation (right).

\section{Integrated Facade Performance Simulation}

\subsection{Background setting of CFD simulation}

Different from the background settings for measuring pressure, the purpose of this simulation is to monitor the wind velocity in the semi-external space. In this case, there are 5 reference points in the semi-external space that are monitored: 1 front, 1 back, 2 corners, and 1 side as Figure 6 (left) shows. As the purpose of the wind blocking façade 
TABLE 2: Background setting of CFD simulation for wind velocity.

Reference wind velocity at the level of $10 \mathrm{~m}$
Turbulence modelling
Boundary condition
Roughness length
Ground level
Wind Direction

$25 \mathrm{~m} / \mathrm{s}$
RANS k-epsilon model
Atmospheric Inlet
0.003
0
90 (Degree)

is to provide livable semi-external space in high rise buildings, the reference wind velocity is different. According to Hong Kong observatory (2018), the mean velocity of the year of 2018 is $23.2 \mathrm{~km} / \mathrm{h}$, where in this project, in order to cover a wider range of wind velocities, $25 \mathrm{~m} / \mathrm{s}$ is taken into account. Table 2 summarises the background information:

\subsection{Simulation results and analysis}

Following the façade design concept, three main facade aspects are tested for their wind blocking performance, based on a typical building floor. Results show that the wind flow behavior can be strategically adjusted by using a multi-layer façade, rectangular façade element cross-sections and strategically placed glass sheets that can serve not only as wind speed reducing elements but can also perform architectural functions such as railings or devices aiding in fire protection. The wind speed simulation shows that best results are obtained for railing placed from the floor level to 1.3m (Figure 9, left) and from $1 \mathrm{~m}$ above floor to $3.1 \mathrm{~m}$ height (Figure 9, right). The effects of these strategies are shown in the below comparative diagrams illustrating changes of wind speed in relation to façade geometry. In general, the corners of the buildings can be singled out as key areas facing excessive wind speeds and requiring increased design attention to allow the façade proposal to achieve its performance aims. In the below diagrams, lower wind speeds are desirable, with $5 \mathrm{~m} / \mathrm{s}$ typically assumed as the limit for human comfort [8]. It may be added that in Hong Kong, a subtropical climate zone with extended hot and humid summers, wind speed at the upper end of the normally assumed comfort zone, may not be seen as detrimental. 


\subsubsection{Double / Single layer façade}
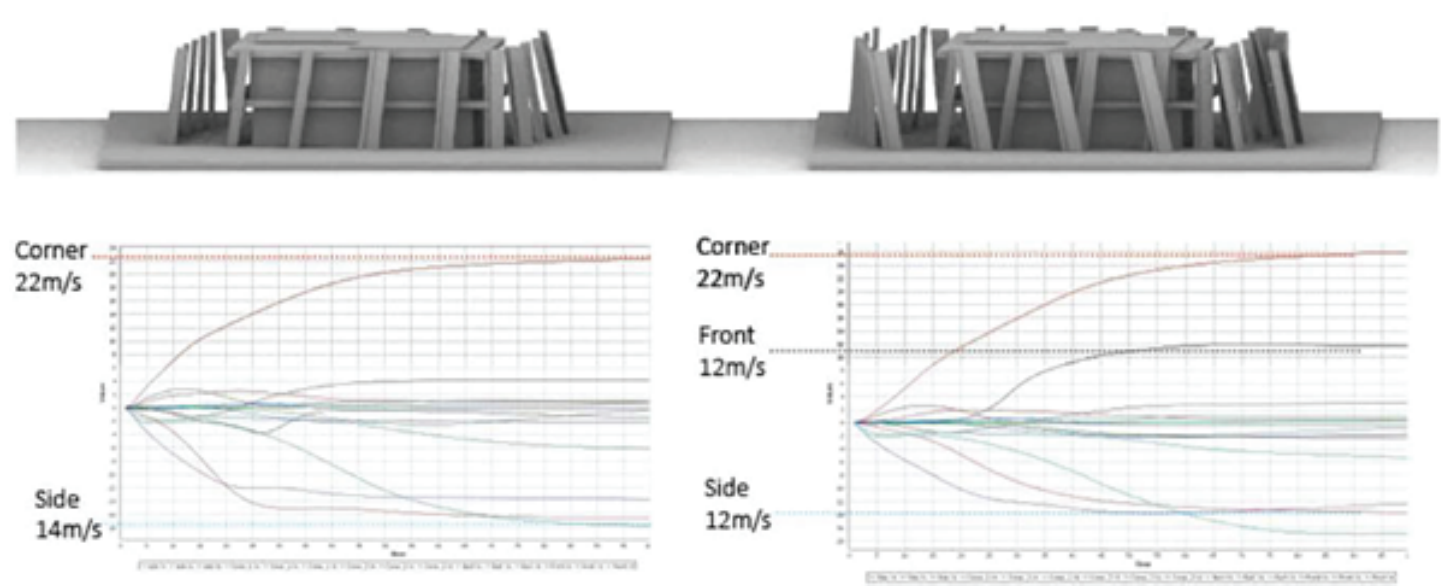

Figure 7: Single layer (left) and double layer (right) facade wind velocity in semi-external space simulation result.

\subsubsection{External façade cross section}

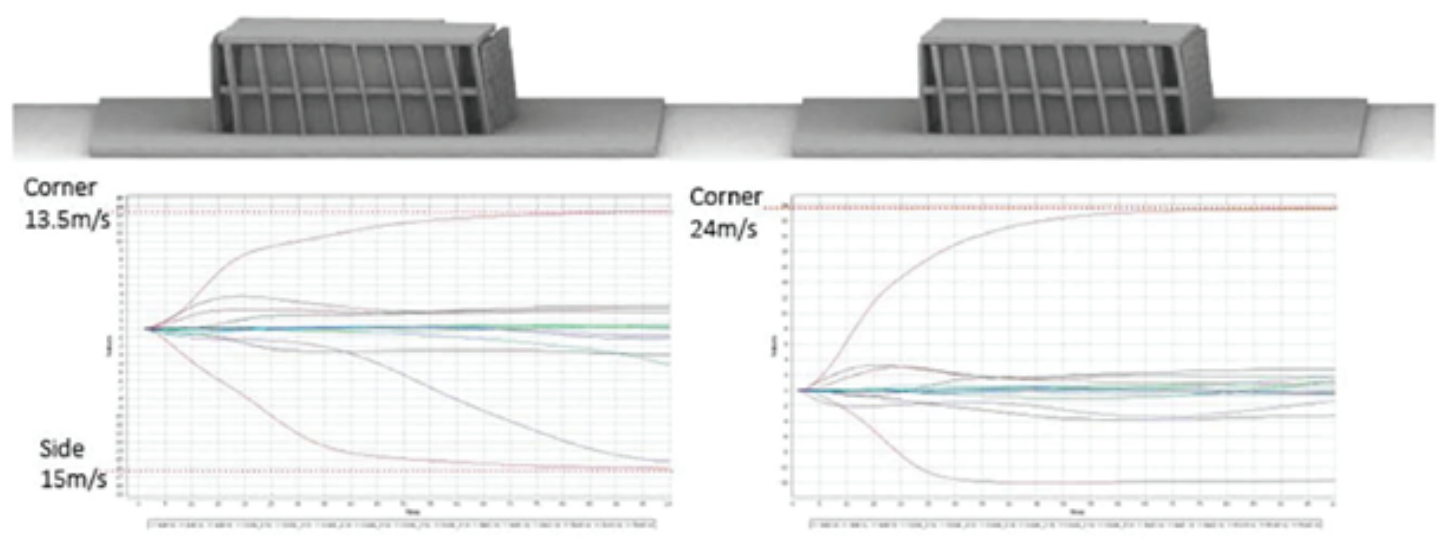

Figure 8: Rectangular (left) and circular (right) cross-section wind velocity in semi-external space.

\subsubsection{Glass railing location}

\section{Discussion}

Based on the results of a range of wind simulation analyses, the cross-disciplinary design team could identify promising strategies for façade design improvements. The main goal of significantly reducing wind speeds to create inhabitable as well as comfortable semi external spaces in high rise buildings was found to be achievable through a combination of strategies including layering of the façade, choosing rectangular element 


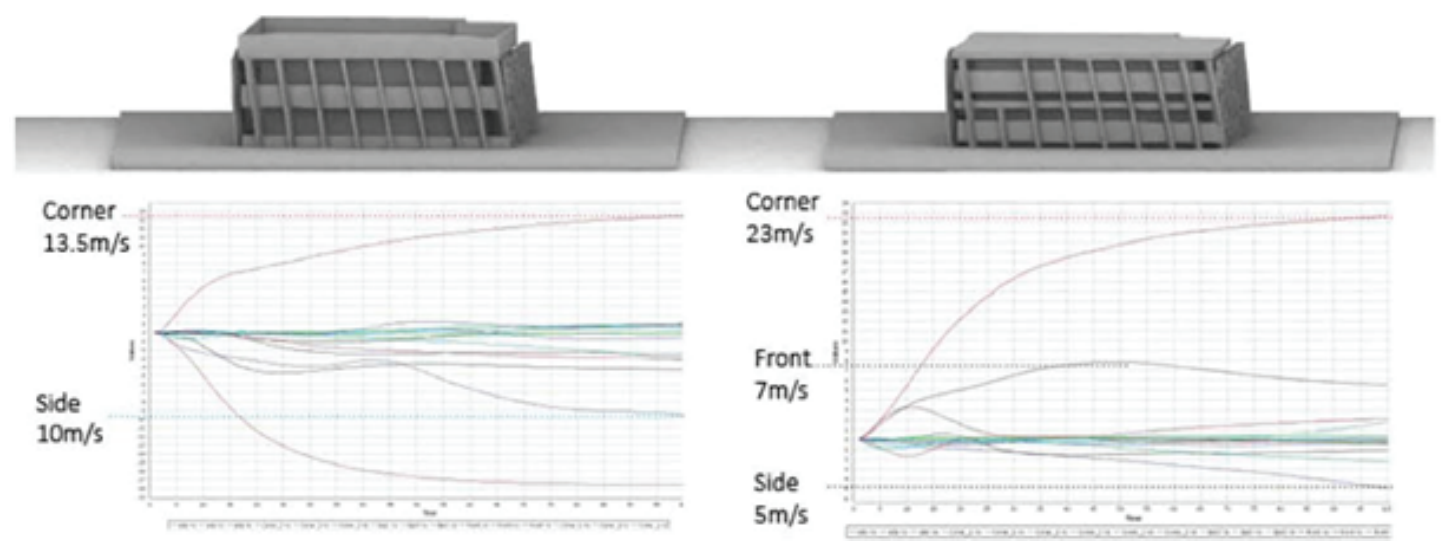

Figure 9: Railing location in relation to wind velocity in semi-external space simulation result.

cross sections, and employing planar railing elements. A selection of these strategies is shown in applied form in Figure 10, which however still requires a translation into an architectural façade proposal. In addition, the strategic location of semi-external spaces in the middle rather than the corner of each floor's façade is found to reduce typically occurring wind speeds to a comfortable level.

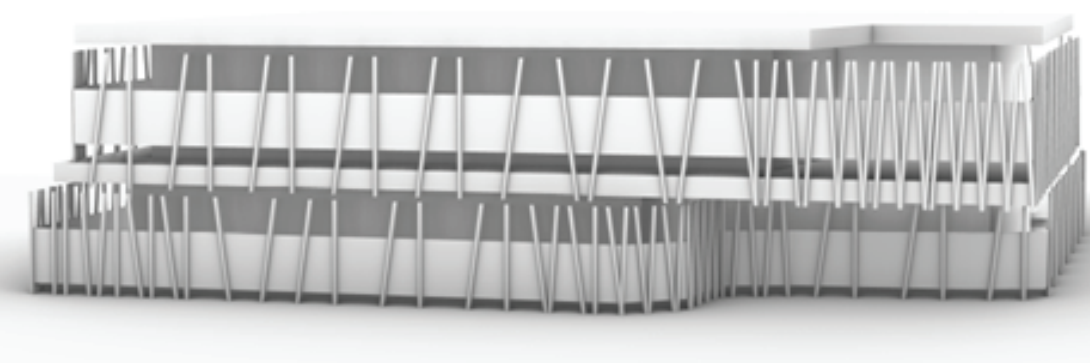

Figure 10: A collection of façade design strategies before translation into an architectural proposal.

\section{Conclusion}

Examining a cross-disciplinary approach to the design of a façade for a conceptual high-rise building proposal for Hong Kong, this paper examines key moments in the design process as well as key simulation tools that informed the design process. From an architectural viewpoint, input from CFD modelling software is a key component in addressing the design goals of the façade, and can generate unexpected and interesting design approaches. From a structural engineering viewpoint, the architectural intentions provide a flexible boundary for providing technical design proposals that 
reach a considerable challenge compared to conventional standardised façade systems. Based on a range of wind simulation analyses, the design team reached not only façade design improvements but could also summarise more general design strategies for wind that will benefit both sides of the design team in future. The project is ongoing and will require several more design cycles to reach the depth of

resolution required from both disciplines, with time and scope of the project context limiting the depth of the project resolution. To its collaborators, the project has led to new understanding of performance- based architectural façade design and demonstrates how applied cross-disciplinary design aided by BIM as a platform for exchange and development can provide a fruitful platform for technical design innovation.

\section{Acknowledgement}

We would like to thank our colleagues at the XJTLU Departments of Architecture and Civil Engineering for supporting cross-disciplinary research in Final Year Projects of the BEng Architectural Engineering programme. We are especially indebted to the generous support and collaboration of Chitraj Bissoonauth, the collaborating architectural designer.

\section{Conflict of Interest}

The authors have no conflict of interest to declare.

\section{References}

[1] Olsen, C. And Mac Namara, S. (2014). Collaborations in architecture and engineering. New York, NY and Oxon, UK: Routledge.

[2] Bisssoonauth, C. (2018). Reef Towers Hong Kong. MArch Des thesis, Xi'an JiaotongLiverpool University.

[3] Yeung, R. (2016) Green for danger: how a trend to put vegetation on Hong Kong's roofs ended in a tangled mess, South China Morning Post, www.scmp.com/ news/hong- kong/health-environment/article/1957404/green-danger-how-trend-putvegetation-hong- kongs, accessed accessed 20th March 2019.

[4] Hong Kong Observatory: www.weather.gov.hk, accessed 20th March 2019.

[5] Herr, C.M. (2018) Creativity Between Architecture and Structural Engineering: Educating Collaborative Practitioners of the Future, in Proceedings of The VI 
International Conference on Engineering Education without Borders, Madrid, pp. 30-38.

[6] Jin, R. (2017), Project-based pedagogy in interdisciplinary building design adopting BIM, Engineering, Construction and Architectural Management 25(10), pp.1376-1397.

[7] Herr, C.M. (2018) Creativity in Cross-disciplinary Collaborations between Architects and Structural Engineers in China, in Proceedings of the 2018 Conference of the International Association for Spatial and Shell Structures (IASS), Boston, MIT, 2018.

[8] Pendwarden, A.D. (1973). Acceptable wind speeds in towns, Building Science vol. 8, pp. 259-267. 